\title{
Hydrogen Bond-Based Macrocyclic and Tripodal Neutral lonophores for Highly Selective Polymeric Membrane Sulfate-Selective Electrodes
}

\author{
Long Li,* Pengcheng Du, Yinghui Duan, Yihao Zhang, Ying Li, Yi Qian, Peidong Zhang, Qingjie Guo, \\ and Jiawang Ding
}

Cite This: ACS Sens. 2021, 6, 245-251

Read Online

ACCESS | Lلll Metrics \& More | 回 Article Recommendations ｜ sl Supporting Information

ABSTRACT: Four hydrogen bond-based macrocyclic and tripodal neutral receptors with increasing conformational complementarity with sulfate were used for the first time as ionophores to develop polymeric membrane sulfate-selective electrodes. Optimizing the membrane composition such as ionophores, lipophilic additives, and plasticizers yielded ISEs which showed Nernstian response to sulfate with the best selectivity so far and improved detection limits (a slope of $-29.8 \mathrm{mV} / \mathrm{dec}$ in the linear range of $1 \times$ $10^{-6}-1 \times 10^{-1} \mathrm{M}$ with a detection limit of $5 \times 10^{-7} \mathrm{M}$ ), which led to the success of the determination of sulfate in drinking water samples and neomycine tablets. The anionionophore complex constants in the membrane phase were determined and correlated with the selectivity sequence of the ISEs. Studies on the influence of $\mathrm{pH}$ of the sample solution demonstrated that the developed ISEs can be operated in a wide $\mathrm{pH}$ range of 3-8 with fast response and rapid (in $1 \mathrm{~min}$ ) and long lifetime. The success of these ionophores represents a feasible strategy for overcoming the "Hofmeister series" by employing a combination of complementarity and hydrogen bonds.

KEYWORDS: polymeric membrane electrode, sulfate, macrocyclic, tripodal, ionophore



$\mathrm{B}$ enefiting from the advent of host-guest chemistry, polymeric membrane ion-selective electrodes (ISEs) fabricated with various ionophores have experienced exponential success in recent years owing to their routine application in clinical, industrial, and environmental fields. ${ }^{1-3}$ It is well established that the performance of ISEs could be predicted by inspecting the binding affinity and selectivity of the ionophores to target ions and interfering ones. ${ }^{4-6}$ Actually, the development of ionophores to selectively complex anions out of aqueous solutions is very challenging, owing to their diverse geometries, larger sizes, $\mathrm{pH}$-dependent structures, low charge densities, and often inherently high hydration energies, especially for the anions (for example, sulfate) at the end of Hofmeister series (organic anions $>\mathrm{ClO}_{4}^{-}>\mathrm{SCN}^{-}>\mathrm{I}^{-} \approx$ salicylate $>\mathrm{NO}_{3}{ }^{-}>\mathrm{Br}^{-}>\mathrm{Cl}^{-}>\mathrm{HCO}_{3}{ }^{-}>\mathrm{HPO}_{4}{ }^{2-} \approx \mathrm{F}^{-} \approx$ $\left.\mathrm{SO}_{4}{ }^{2-}\right) .^{7-10}$ Sulfate is among the most abundant and important macronutrients in cells and human plasma and is involved in the biosynthesis and detoxification of many endogenous/exogenous compounds. Also, a sulfate ion has been regarded as an end product of the metabolic process of sulfur-containing amino acids. Moreover, high concentrations of inorganic sulfate in drinking water might be related to diarrhea. ${ }^{11,12}$ Therefore, there is an urgent need for sulfate determination in clinical, environmental, and pharmaceutical fields.

Several kinds of interactions or functional groups such as Lewis acid-base interactions, electrostatic forces, hydrogenbonding ( $\mathrm{HB})$, and halogen-bonding (XB) have been employed in anion recognition chemistry to develop anion receptors. ${ }^{13-16}$ However, only a part of these receptors have been proved to be good ionophores for polymeric membrane anion-selective electrodes, indicating that it is not so straightforward to correlate the binding data in a simple solvent directly with the performance the ISEs. ${ }^{17,18}$ First, bis(thiourea) and bis(guanidinium) derivatives with a xylene spacer were used as ionophores for potentiometric sulfate detection; although the interference of several lipophilic anions was significantly reduced, the reported selectivity coefficients were not satisfactory for real-life application. ${ }^{19,20}$ Learning from the recognition site of the sulfate-binding protein, a tripodal receptor molecule was synthesized by anchoring three urea groups on a tris(2-aminoethylamine) scaffold; sulfate complexation could be achieved through $\mathrm{H}$-bonds in a three-

Received: October 25, 2020

Accepted: December 15, 2020

Published: December 29, 2020

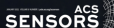


Scheme 1. Structures of the Ionophores Used for Polymeric Membrane Sulfate Electrodes in This Work

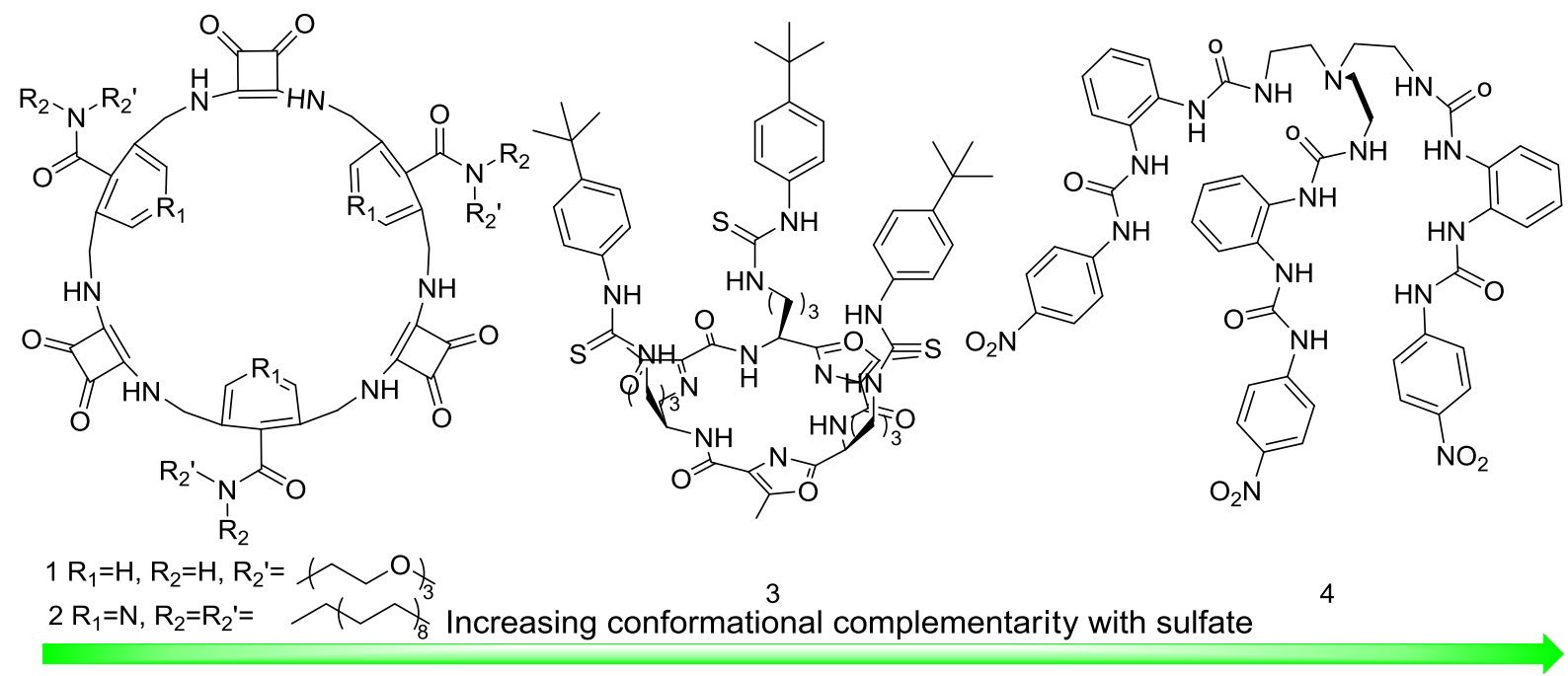

dimensional cavity. ${ }^{20}$ There is no doubt that molecules with the same tris(2-aminoethylamine) scaffold and more acidic squaramide legs also work well for sulfate recognition. ${ }^{9}$ Although polymeric membrane sulfate-selective electrodes formulated with urea or squaramide-based tripodal ionophores showed an anti-Hofmeister response, and the latter electrodes have been used for sulfate determination in drinking water and cell lysates, it should be noticed that the interference from lipophilic ions is still significant. ${ }^{9,20}$

Besides the method mentioned before, more strategies can be envisioned by manipulating the topology of the ionophores. Macrocyclic compounds (see 1 and 2 in Scheme 1) containing alternating aryl spacers and squaramides have been synthesized by Elmes and proved to be sulfate-selective receptors with high association constants $\left(>10^{4} \mathrm{M}^{-1}\right.$ in organic/aqueous solutions), which can be ascribed to the matched size and shape of sulfate with the preorganized cavity. ${ }^{21-23}$ It has been reported that tripodal urea or squaramide-based ionophores encapsulate tetrahedral sulfate in a 2:1 (host/guest) fashion, in which one of the ligands is a conformational complement with the three edges, but the other one faces the vertices of the bottom triangular plane of the tetrahedron. ${ }^{24,25}$ It is obvious that complementarity for the sulfate is not optimal in this case, and calculations have demonstrated that the optimal saturated coordination mode for sulfate is binding in a complementary tetrahedral cavity with 12 optimally arranged hydrogen bonds along the edges. ${ }^{25}$ Along this line, on the one hand, by substituting the tris(2-aminoethylamine) scaffold of the tripodal ionophores with cyclic peptide, Jolliffe developed a shielding cavity with high sulfate affinity (see 3 in Scheme 1). ${ }^{26}$ On the other hand, $\mathrm{Wu}$ extended the three monourea legs of the tris(2-aminoethylamine) scaffold to an ortho-phenyl bridged bisurea to produce a hexaurea ligand that shows saturated coordination of a sulfate ion (see 4 in Scheme 1). ${ }^{27}$ Competitive experiments with other competitive anions demonstrated that this tripodal hexaurea could selectively bind sulfate with an association constant larger than $10^{4} \mathrm{M}^{-1}$ in DMSO $/ 25 \% \mathrm{H}_{2} \mathrm{O}$, and almost quantitative extraction of sulfate ions from an aqueous to an organic phase could be achieved. ${ }^{27}$

On account of their selectivity and the relatively high binding constants of receptors 1-4 with sulfate in solutionphase measurements, we herein evaluated their performance as new ionophores for polymeric membrane sulfate-selective electrodes. Different membrane components such as plasticizers and lipophilic additives were optimized to improve the detection sensitivity and selectivity. Binding constants of the ionophore-sulfate complexes in the membrane phase were determined by a segmented sandwich membranes method and correlated with the selectivity coefficients. Finally, the proposed polymeric membrane sulfate-selective electrode was applied for sulfate determination in real-life samples.

\section{EXPERIMENTAL SECTION}

Reagents. All ionophores were supplied by Qingdao Zhongke Chemicals, prepared as described in the literature. ${ }^{21-23,26,27}$ High molecular weight poly(vinyl chloride) (PVC), 2-nitrophenyl octyl ether (o-NPOE), bis(2-ethylhexyl) sebacate (DOS), and tridodecylmethylammonium chloride (TDMACl) were purchased from Sigma. 2-Fluorophenyl 2-nitrophenyl ether (FPNPE) was acquired from Heowns (Tianjin Heowns Biochem LLC). Other reagents were purchased from Sinopharm Group Co., Ltd. All chemicals were of selectophore or analytical reagent grade. Aqueous solutions were prepared with fresh deionized water (18.2 $\mathrm{M} \Omega \mathrm{cm}$ specific resistance) obtained using a Pall Cascada laboratory water system.

Membrane and Electrode Preparation. Polymeric membrane electrodes were prepared using a solvent casting technique according to established procedures reported elsewhere. ${ }^{6}$ Briefly, specific amounts of the ionophores, TDMACl, and DOS, NPOE, or FPNPE plasticizers were dissolved in THF to prepare membrane cocktails. After transferring the membrane cocktail to a glass ring fixed on a glass plate and evaporation of the tetrahydrofuran overnight, a uniform polymeric liquid membrane (ca. $200 \mu \mathrm{m}$ in thickness) was obtained. Subsequently, the as-formed membrane was cut into small disks of $7 \mathrm{~mm}$ diameter using a cork borer to install onto Philips IS561 electrode bodies. A solution of HEPES $(20 \mathrm{mM}, \mathrm{pH}=7.0)$ buffer with the addition of $\mathrm{Na}_{2} \mathrm{SO}_{4}(10 \mathrm{mM})$ was used as the internal filling solution except otherwise mentioned. Membranes were conditioned in the internal filling solution overnight before evaluating the potentiometric performance. To prepare the sandwich membranes, a set of disks from membranes with or without ionophores were conditioned separately for 2 days in $1 \times 10^{-2} \mathrm{M}$ solution of specific anions prepared with HEPES $(20 \mathrm{mM}, \mathrm{pH}=7.0)$ buffer. After drying with filter paper, the sandwich membrane was then assembled by attaching the membrane with the ionophore to the ionophore-free membrane. The sandwich membrane was then mounted immediately in the electrode body.

Potentiometric Measurements. Potentiometric measurements were carried out using a CHI $660 \mathrm{C}$ electrochemical station (Shanghai 
Table 1. Compositions of the Membranes, Selectivity Coefficients and Characteristics of the Potentiometric Response toward Sulfate for Electrodes with PVC/Plasticizer (1:2) Membranes Containing 1 wt \% Ionophores and TDMACl (mol \%)

\begin{tabular}{|c|c|c|c|c|c|c|c|c|c|c|c|c|}
\hline \multirow[b]{2}{*}{ ISEs } & \multirow[b]{2}{*}{ ionophore } & \multirow[b]{2}{*}{ TDMACl $(\mathrm{mol} \%)^{a}$} & \multirow[b]{2}{*}{ plasticizer } & \multirow[b]{2}{*}{ slope $(\mathrm{mV} / \mathrm{dec})$} & \multirow[b]{2}{*}{ detection limit (M) } & \multicolumn{7}{|c|}{$\log K_{\text {sulfate, }} \mathrm{x}^{- \text {pot. } b}$} \\
\hline & & & & & & $\mathrm{ClO}_{4}^{-}$ & $\mathrm{I}^{-}$ & $\mathrm{SCN}^{-}$ & $\mathrm{NO}_{3}^{-}$ & $\mathrm{Br}^{-}$ & $\mathrm{Cl}^{-}$ & $\mathrm{H}_{2} \mathrm{PO}_{4}^{-}$ \\
\hline 0 & & 1 wt $\%$ & $o$-NPOE & 18.1 & $1 \times 10^{-3}$ & 7.6 & 5.9 & 7.0 & 5.6 & 4.5 & 3.4 & 2.5 \\
\hline I & 1 & $30 \%$ & $o$-NPOE & 28.7 & $1 \times 10^{-6}$ & 0.3 & -0.1 & -0.2 & -0.5 & -1.8 & -2.2 & -4.0 \\
\hline II & 2 & $10 \%$ & $o$-NPOE & 25.6 & $4 \times 10^{-7}$ & 0.3 & -0.4 & -0.6 & -1.3 & -1.6 & -2.6 & -4.2 \\
\hline III & 2 & $30 \%$ & $o$-NPOE & 29.5 & $5 \times 10^{-7}$ & 0.2 & -0.5 & -0.9 & -1.6 & -2.0 & -2.8 & -4.6 \\
\hline IV & 2 & $50 \%$ & $o$-NPOE & 27.4 & $1 \times 10^{-6}$ & 0.4 & -0.6 & -0.7 & -1.3 & -1.8 & -2.6 & -4.3 \\
\hline $\mathrm{V}$ & 2 & $30 \%$ & DOS & 23.2 & $5 \times 10^{-6}$ & 0.6 & -0.1 & 0.3 & -0.2 & -1.4 & -2.0 & -4.0 \\
\hline VI & 3 & $10 \%$ & $o$-NPOE & 22.6 & $8 \times 10^{-7}$ & 1.4 & 1.6 & 1.4 & -0.1 & -0.7 & -2.0 & -4.0 \\
\hline VII & 3 & $30 \%$ & $o$-NPOE & 28.2 & $1 \times 10^{-6}$ & 1.5 & 1.0 & 1.2 & -0.2 & -1.2 & -2.3 & -4.2 \\
\hline VIII & 3 & $50 \%$ & $o$-NPOE & 25.3 & $3 \times 10^{-6}$ & 1.8 & 1.6 & 1.5 & -0.1 & -0.5 & -2.4 & -4.0 \\
\hline IX & 4 & $30 \%$ & FPNPE & 28.5 & $3 \times 10^{-7}$ & 0.6 & -0.3 & -0.1 & -1.5 & -2.5 & -3.7 & -4.6 \\
\hline $\mathrm{X}$ & 4 & $50 \%$ & FPNPE & 29.8 & $5 \times 10^{-7}$ & 0.3 & -0.8 & -0.5 & -1.8 & -2.8 & -4.1 & -5.3 \\
\hline XI & 4 & $70 \%$ & FPNPE & 25.2 & $1 \times 10^{-6}$ & 3.5 & -0.4 & -0.3 & -1.3 & -2.1 & -3.8 & -4.1 \\
\hline $\mathrm{XII}^{c}$ & 3 & $30 \%$ & FPNPE & 28.0 & $1 \times 10^{-6}$ & 1.4 & 0.8 & 1.1 & -0.2 & -1.4 & -2.3 & -4.4 \\
\hline $\mathrm{XIII}^{c}$ & 4 & $50 \%$ & FPNPE & 29.5 & $5 \times 10^{-7}$ & 0.2 & -0.7 & -0.6 & -1.8 & -2.9 & -4.0 & -5.2 \\
\hline
\end{tabular}

${ }^{a}$ Relative to the ionophore. ${ }^{b}$ Separated solution method, theoretical slopes. ${ }^{c}$ Polyurethane/FPNPE (1:1) membranes.

Chenhua Apparatus) at room temperature with $\mathrm{Ag} / \mathrm{AgCl}(3 \mathrm{M} \mathrm{KCl})$ as a reference electrode in the galvanic cell: $\mathrm{Ag} / \mathrm{AgCl} 3.0 \mathrm{M} \mathrm{KClll} 1.0$ $\mathrm{M} \mathrm{CH}_{3} \mathrm{COOLillsample} \mathrm{solution|ISE} \mathrm{membranelinner} \mathrm{filling} \mathrm{solutionl}$ $\mathrm{Ag} / \mathrm{AgCl}$. The selectivity coefficients were determined by a separated solution method, the potentials in two separate solutions (each containing a salt of the determined ion only) were recorded, and the values obtained at the highest examined concentrations were used to calculate the selectivity coefficient assuming theoretical slopes. ${ }^{28}$ The complex formation constants were determined by the method described by Bakker. ${ }^{29}$

\section{RESULTS AND DISCUSSION}

As shown in Scheme 1, four receptors with three different kinds of topology and increasing conformational complementarity with sulfate were used as ionophores here. Macrocyclic compound 1 was obtained by organizing aryl spacers and squaramides in an alternating fashion to match the size and shape of sulfate, which can sit comfortably in the cavity of the macrocycle. ${ }^{21}$ Further preorganization and thus improved binding affinity and selectivity were achieved when benzene spacer units were replaced by pyridines ( 2 in Scheme 1), owing to the formation of intramolecular hydrogen bonds between the pyridine nitrogen and amide protons. ${ }^{22,23}$ Considering the success of using tris(2-aminoethylamine) scaffold-based ionophores for potentiometric sulfate detection, it is reasonable that compound 3 with similar topology but more functional cyclic peptide amide hydrogen bond donors should also work well. ${ }^{26}$ Last but most important, compound 4 could reposition its ortho-phenyl bridged bisurea legs to accommodate the tetrahedral sulfate with perfect conformational complementarity and might be the only receptor reported to date that displays saturated coordination to sulfate by a single molecule. ${ }^{27}$ In general, ionophores $1-2$ are cyclic molecules favoring planar complexation of sulfate, while ionophores 3-4 are tripodal hosts that can provide cavities to accommodate sulfate with anchored functional groups in three dimension, this is true especially for collapsible legs bearing ionophore 4 .

As shown in Table 1 and Figure 1, polymeric membrane electrodes formulated with all of the four ionophores 1-4 exhibit Nernstian/near-Nernstian response toward sulfate and selectivity patterns significantly different from the Hofmeister series, confirming the strong ionophore properties and high binding affinity of sulfate to ionophores. The nature of the

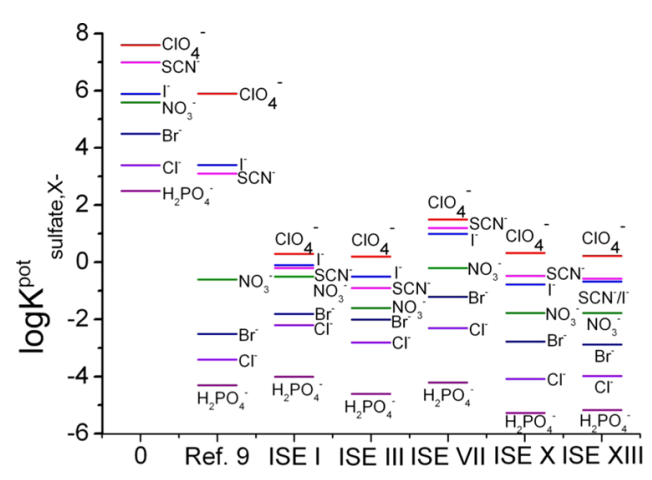

Figure 1. Potentiometric selectivity coefficients of tripodal squaramide ionophore-based electrodes from ref 9, ISE I, ISE III, ISE VII, ISE X, and ISE XIII toward sulfate over different anions.

plasticizers exerts a significant influence on the dielectric constant of the membrane and the mobility of the ionophore. A higher dielectric constant increases the polarity and decreases the electrical resistance of the membrane. ${ }^{6}$ Since ionophores 3 and 4 had poor solubility in DOS $(\varepsilon=4.8)$ and/ or $o$-NPOE $(\varepsilon=24)$, more polar $o$-NPOE and FPNPE $(\varepsilon=$ 50) were chosen for ionophores 3 and 4, respectively. The results showed that DOS-plasticized electrodes demonstrated lower slopes, higher detection limits, and poor selectivity than those plasticized with NPOE (see ISE III and V in Table 1, which have the same composition but different plasticizer).

Lipophilic sites could compensate the charges of the anionionophore complex at high concentrations and improve the sensitivity, and thus the influence of a lipophilic additive on the performance of the electrodes containing different ionophores was evaluated. ${ }^{5}$ Although little differences in the slopes of ISEs IX-XI were observed when changing the amount of additives, the amount of TDMACl does have a significant influence on the slopes of ionophore 2 and 3-based ISEs. For ionophores 2-4-based membranes, modest contents of TDMACl are necessary to obtain optimal slopes, and selectivity (30 mol \% for ionophores $1-3$ and $50 \mathrm{~mol} \%$ for ionophore 4, ISEs I, III, VII, and X), and lower or higher contents may deteriorate the performance. Unfortunately, electrodes with optimized sulfate selectivity (ISE III, VII, and X) did not show the best detection 
limits (ISE II, VI, and IX). Similar anti-Hofmeister selectivity pattern $\left(\mathrm{ClO}_{4}{ }^{-}>\mathrm{SO}_{4}{ }^{2-}>\mathrm{I}^{-} \approx \mathrm{SCN}^{-}>\mathrm{NO}_{3}{ }^{-}>\mathrm{Br}^{-}>\mathrm{Cl}^{-}>\right.$ $\mathrm{H}_{2} \mathrm{PO}_{4}{ }^{-}$) was observed for the ISEs developed with ionophores 1, 2, and 4, while ISEs fabricated with ionophore 3 prefer lipophilic anions $\left(\mathrm{ClO}_{4}^{-}>\mathrm{I}^{-} \approx \mathrm{SCN}^{-}>\mathrm{SO}_{4}{ }^{2-}>\right.$ $\left.\mathrm{NO}_{3}^{-}>\mathrm{Br}^{-}>\mathrm{Cl}^{-}>\mathrm{H}_{2} \mathrm{PO}_{4}^{-}\right)$, and it is interesting to find that the performance sequence of the ionophores follow the trend 4 $>2>1>3>$ squaramide-based tripodal ionophore (see Figure $1)$. These results are counterintuitive considering more conformational complementary properties and additional hydrogen bond donating ability of ionophore 3, compared with ionophores 1-2 and squaramide-based tripodal ionophore (from ref 9), respectively. However, these results are consistent with the observation that ionophore 2 and tripodal squaramide showed high bulk liquid membrane and lipid bilayer sulfate transport activity, while ionophore 3 did not work under similar conditions. ${ }^{2,30}$ Moreover, solvation of the ionophores and anions, as well as aggregation of ionophores, may play major roles in this process. Apparently, the best selectivity values for our proposed ISE over $\mathrm{H}_{2} \mathrm{PO}_{4}^{-}, \mathrm{Cl}^{-}, \mathrm{Br}^{-}$, $\mathrm{NO}_{3}{ }^{-}, \mathrm{SCN}^{-}, \mathrm{I}^{-}$, and $\mathrm{ClO}_{4}{ }^{-}$are $-5.3,-4.1,-2.8,-1.8,-0.5$, -0.8 , and +0.3 , which are $1.0,0.7,0.3,1.2,3.6,4.2$, and 5.6 units better than previously reported best selectivity (the best selectivity coefficients of sulfate-selective sensors over $\mathrm{H}_{2} \mathrm{PO}_{4}{ }^{-}$, $\mathrm{Cl}^{-}, \mathrm{Br}^{-}, \mathrm{NO}_{3}^{-}, \mathrm{SCN}^{-}, \mathrm{I}^{-}$, and $\mathrm{ClO}_{4}^{-}$are $-4.3,-3.4,-2.5$, $-0.6,+3.1,+3.4$, and +5.9 , respectively). ${ }^{9}$ It is obvious that although the improvement in selectivity over hydrophilic anions is not significant, interference from lipophilic anions such as $\mathrm{SCN}^{-}, \mathrm{I}^{-}$, and $\mathrm{ClO}_{4}{ }^{-}$is reduced largely, which are the most relevant ions for sulfate detection in environmental and clinical samples. It should be mentioned that the selectivity coefficients were determined by a separate solution method, which makes it possible to selectivity coefficient compare data of the new ionophores with those of the previously reported ionophores. In parallel, potentiometric response curves toward various anions are also illustrated (see Figure 2).

The effects of $\mathrm{pH}(3-11)$ on macrocyclic and tripodal ionophore-based membrane electrodes (ISEs I, III, VII, and X) were investigated by recording the potential change in $1 \mathrm{mM}$ sulfate solution prepared with deionized water, to which very small aliquots of $0.1 \mathrm{M} \mathrm{NaOH}$ or $\mathrm{HCl}$ was added to adjust the $\mathrm{pH}$. As shown in Figure 3, the potential responses of ISEs I, VII, and $\mathrm{X}$ were independent of $\mathrm{pH}$ in the range of 3-8, further increasing the $\mathrm{pH}$ of the solution to a higher range of $8-11$ resulted in a negative slope of $10-50 \mathrm{mV} / \mathrm{pH}$. The negative potential responses in the $\mathrm{pH}$ range of $8-11$ might be attributed to the binding of $\mathrm{OH}^{-}$by the ionophores embedded in the membrane phase. It is interesting to find that ISE III displayed a positive potential response to $\mathrm{H}^{+}$in the $\mathrm{pH}$ range of 3-5, and the surprising response might be ascribed to the protonation of the isonicotinamide units $\left(\mathrm{p} K_{\mathrm{a}}=3.3\right)$ in the macrocycle, which could provide additional electrostatic interactions with the anion and thus increase the binding affinity. ${ }^{22}$ An example of the dynamic response of representative ISE $X$ to sulfate is presented in Figure 4. Although a little potential drift was observed when changing the concentration of sulfate, the response time was considerably shorter $(<60 \mathrm{~s})$. To give more information about the reversibility, potential traces when switching sensors from high to low concentrations several times are also displayed in Figure 4. It seems that although strong complexation (see the ionophore-anion complex formation constants) with sulfate is observed, good reversibility is obtained, and similar phenomena have been
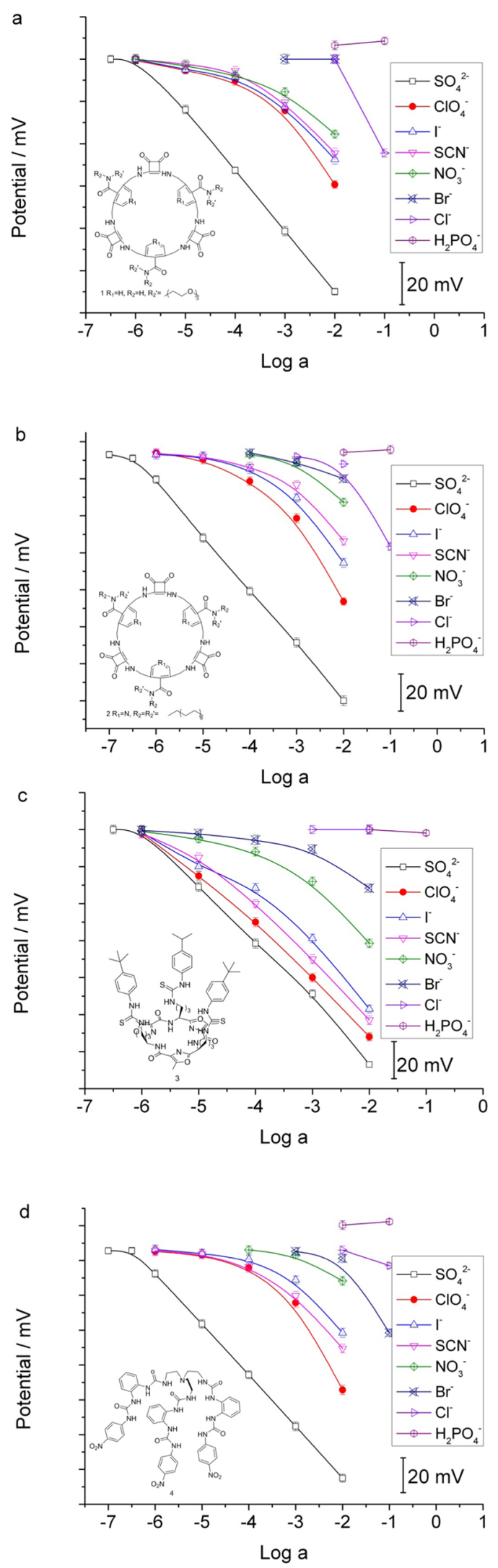

Figure 2. Potentiometric responses of ISE I (a), III (b), VII (c), and $\mathrm{X}(\mathrm{d})$ toward different anions.

reported in a previous work. ${ }^{31,32}$ Moreover, the stability of ISEs I, III, VII, and X has been evaluated over a period of 2 months. While no significant changes in the slopes, detection limit, and 


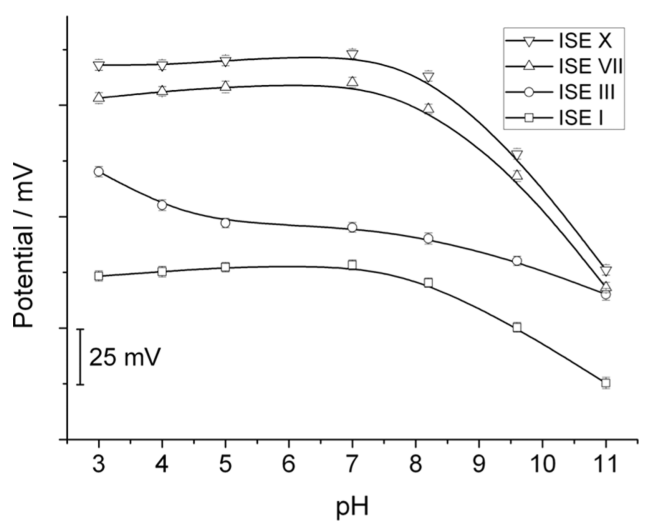

Figure 3. Effects of $\mathrm{pH}$ on the potential responses of ISEs I, III, VII, and $\mathrm{X}$.

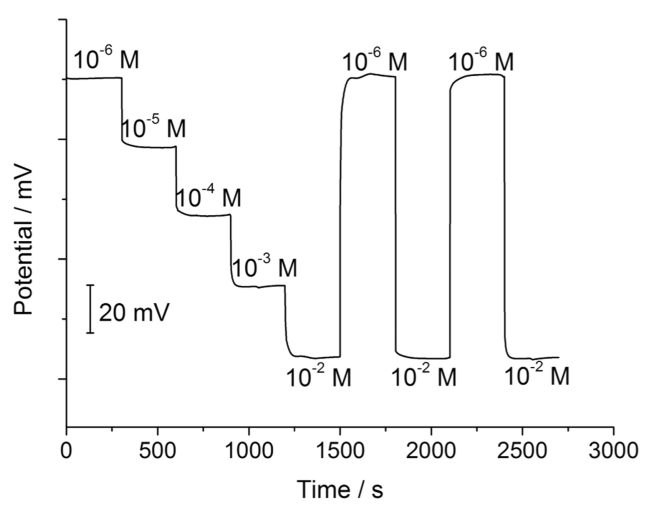

Figure 4. Dynamic sulfate EMF response of ISE X (HEPES buffer, $\mathrm{pH}=7.0)$.

selectivity coefficients were observed for ISEs I and III, only 22 and $20 \mathrm{mV} / \mathrm{dec}$ responses were observed for ISEs VII and X, originating from the crystallization of the ionophores 3 and 4 in the membrane phase. To solve this problem, polymeric membrane electrodes have been fabricated by embedding the ionophores 3 and 4 in FPNPE plasticized polyurethane membrane. It is obvious that no significant changes in potentiometric responses were observed for ISEs XII and XIII in 2 months, demonstrating their satisfying stability (see Table S1 in the Supporting Information). Moreover, further structure refinement such as anchoring long lipophilic alkyl chains on the aromatic moieties of ionophore 4 is in progress in our lab.

It is well established that the binding affinity of ionionophore complexes have significant influence on the selectivity of the ISEs. However, translating the binding data in the solution-phase to the selectivity of the ionophore-based ISEs is not so straightforward. Herein, the formation constants for ionophores $1-4$ and various anions in $o$-NPOE or FPNPE plasticized membranes are determined using the segmented sandwich method. As shown in Table 2, each ionophore formed its strongest complexes with sulfate, but the sequence of the formation constants of the anion-ionophore complex did not correlate well with the determined selectivity pattern of the ISEs, indicating that the difference between the formation constants for sulfate and other interring anions cannot be translated equivalently to selectivity. Using ionophore 4 as an example, the difference between the formation constants for sulfate and perchlorate is 8.0, whereas the related best $\log K_{\text {sulfate, anion }}{ }^{\text {pot. }}$ is 0.2 . This difference could partly be ascribed to different thermodynamics of ions, and the ion flux across the membrane generated by coextraction and ion-exchange processes. ${ }^{17}$ Actually, the ratio of the complex formation constants of an ionophore with various ions changes the selectivity pattern as compared to Hofmeister series. Although the determination was executed in a different plasticized membrane environment, it can be concluded that compound 4 was the most powerful ionophore, following which was ionophore 2, ionophore 1, and ionophore 3. Similar results have also been mentioned and discussed in the previous section, emphasizing the important roles of size matching (ionophores 1 and 2) and conformational complementarity (ionophore 4) played in anion binding. Determination of the binding affinity of ionophore 2 with sulfate at $\mathrm{pH} 3.0$ gave a $K_{\mathrm{a}}$ of $6.3 \times 10^{10} \mathrm{M}\left(\log K_{\mathrm{a}}=10.8\right)$, approximately double of that observed in a neutral environment $\left(3.2 \times 10^{8} \mathrm{M}, \log K_{\mathrm{a}}=\right.$ $10.5)$, these data correlated well with the results obtained in binary $\mathrm{H}_{2} \mathrm{O} /$ DMSO solution. ${ }^{22}$

As described above, the performance (with a linear range of $1 \times 10^{-6}-1 \times 10^{-1} \mathrm{M}$ and detection limit of $5 \times 10^{-7} \mathrm{M}$ ) of ISE $X$ suggests that it may be suited for real-life applications. Therefore, sulfate determination in drinking water samples and neomycine tablets were performed using the ISE $\mathrm{X}$ and turbidimetry method. As shown in Table 3, the results

Table 3. Analytical Results for the Determination of Sulfate in Drinking Water Samples and Neomycine Tablets $(n=3)$

\begin{tabular}{cccc} 
samples & added $(\mathrm{mM})$ & ISE X $(\mathrm{mM})$ & turbidimetry $(\mathrm{mM})$ \\
drinking water 1 & 1.0 & $0.92 \pm 0.03$ & $0.98 \pm 0.02$ \\
drinking water 2 & 2.0 & $1.90 \pm 0.05$ & $2.02 \pm 0.03$ \\
neomycine tablet 1 & & $1.02 \pm 0.05$ & $0.98 \pm 0.04$ \\
neomycine tablet 2 & & $0.96 \pm 0.06$ & $0.99 \pm 0.03$ \\
\hline
\end{tabular}

obtained using the developed electrode are consistent with those obtained by the turbidimetry method, proving its reliability for sulfate detection in environmental and pharmaceutical fields.

Table 2. Ionophore-Anion Complex Formation Constants Determined in PVC/o-NPOE or FPNPE (1:2) Membranes ${ }^{a}$

\begin{tabular}{|c|c|c|c|c|c|c|c|c|c|}
\hline \multirow[b]{2}{*}{ ionophore ( 1 wt \%) } & \multirow[b]{2}{*}{ plasticizer } & \multicolumn{8}{|c|}{ formation constants $\left(\log K_{\mathrm{a}}\right)$} \\
\hline & & $\mathrm{SO}_{4}{ }^{2-}$ & $\mathrm{ClO}_{4}^{-}$ & $\mathrm{I}^{-}$ & $\mathrm{SCN}^{-}$ & $\mathrm{NO}_{3}^{-}$ & $\mathrm{Br}^{-}$ & $\mathrm{Cl}^{-}$ & $\mathrm{H}_{2} \mathrm{PO}_{4}^{-}$ \\
\hline 1 & $o$-NPOE & 10.0 & 2.5 & 4.0 & 2.6 & 4.0 & 4.1 & 4.5 & 3.0 \\
\hline \multirow[t]{2}{*}{2} & $o$-NPOE & 10.5 & 2.6 & 4.1 & 2.6 & 4.1 & 4.3 & 4.7 & 3.2 \\
\hline & $\mathrm{pH}=3.0$ & 10.8 & 2.9 & 4.2 & 2.8 & 4.3 & 4.6 & 4.9 & 3.3 \\
\hline 3 & $o$-NPOE & 9.9 & 3.2 & 4.2 & 3.2 & 4.3 & 4.4 & 4.5 & 3.4 \\
\hline 4 & FPNPE & 11.7 & 3.7 & 4.5 & 3.6 & 4.6 & 4.8 & 4.9 & 4.1 \\
\hline
\end{tabular}

${ }^{a}$ The measurement was operated in HEPES buffer $(\mathrm{pH}=7.0)$ unless otherwise stated. The complex stoichiometry is $1: 1$. 


\section{CONCLUSIONS}

Four hydrogen bond-based macrocyclic and tripodal neutral receptors with increasing conformational complementarity with sulfate were used as ionophores to develop polymeric membrane sulfate-selective electrodes. By optimizing the membrane composition such as ionophores, lipophilic additives, and plasticizers, the proposed ISEs showed Nernstian response to sulfate with the best selectivity so far and improved detection limits (a slope of $-29.8 \mathrm{mV} / \mathrm{dec}$ in the linear range of $1 \times 10^{-6}-1 \times 10^{-1} \mathrm{M}$ with a detection limit of $5 \times 10^{-7} \mathrm{M}$ ), which led to the success of the determination of sulfate in drinking water samples and neomycine tablets. The anion-ionophore complex constants in the membrane phase were determined and correlated with the selectivity sequence of the ISEs. The success of the ionophores represents a feasible strategy for overcoming the "Hofmeister series" by employing a combination of complementarity and hydrogen bonds.

\section{ASSOCIATED CONTENT}

\section{(s) Supporting Information}

The Supporting Information is available free of charge at https://pubs.acs.org/doi/10.1021/acssensors.0c02231.

Data for slopes, detection limits, and selectivity coefficients of ISEs XII and XIII in a period of 2 months (PDF)

\section{AUTHOR INFORMATION}

\section{Corresponding Author}

Long Li - College of Environment and Safety Engineering, Qingdao University of Science and Technology, Qingdao 266042, P. R. China; ○ orcid.org/0000-0003-1074-1825; Phone: +86 532 84022020; Email: lilongyln@yeah.net

\section{Authors}

Pengcheng Du - College of Environment and Safety Engineering, Qingdao University of Science and Technology, Qingdao 266042, P. R. China

Yinghui Duan - College of Chemical Engineering, Qingdao University of Science and Technology, Qingdao 266042, P. R. China

Yihao Zhang - College of Environment and Safety Engineering, Qingdao University of Science and Technology, Qingdao 266042, P. R. China

Ying Li - College of Environment and Safety Engineering, Qingdao University of Science and Technology, Qingdao 266042, P. R. China

Yi Qian - College of Chemical Engineering, Qingdao University of Science and Technology, Qingdao 266042, P. R. China

Peidong Zhang - College of Environment and Safety Engineering, Qingdao University of Science and Technology, Qingdao 266042, P. R. China

Qingjie Guo - State Key Laboratory of High-Efficiency Utilization of Coal and Green Chemical Engineering, Ningxia University, Yinchuan 750021, P. R. China

Jiawang Ding - Key Laboratory of Coastal Environmental Processes and Ecological Remediation and Shandong Provincial Key Laboratory of Coastal Environmental Processes, Yantai Institute of Coastal Zone Research (YIC), Chinese Academy of Sciences (CAS), Yantai, Shandong 264003, P. R. China; Laboratory for Marine Biology and
Biotechnology, Qingdao National Laboratory for Marine Science and Technology, Qingdao 266200, P. R. China

Complete contact information is available at:

https://pubs.acs.org/10.1021/acssensors.0c02231

\section{Notes}

The authors declare no competing financial interest.

\section{ACKNOWLEDGMENTS}

This work was financially supported by the Key R\&D Project of Shandong Province (Nos. 2019CSF109001 and 2019CSF109080), the Shandong Provincial Natural Science Foundation, China (No. ZR2018BB072), the Original Innovation Project of Qingdao City (No. 19-6-2-23-cg), the Foundation of State Key Laboratory of High-efficiency Utilization of Coal and Green Chemical Engineering (Nos. 2018-K09 and 2018-K43), the Key Laboratory of Coastal Environmental Processes and Ecological Remediation, YICCAS (No. 2018KFJJ02), the Opening Project of Shandong Ecochemical Engineering Collaborative Innovation Center (No. XTCXQN02), and the Open Project of Chemistry Department of Qingdao University of Science and Technology (No. QUSTHX201920).

\section{REFERENCES}

(1) Zdrachek, E.; Bakker, E. Potentiometric sensing. Anal. Chem. 2019, 91, 2-26.

(2) Bakker, E. Electroanalysis with membrane electrodes and liquidliquid interfaces. Anal. Chem. 2016, 88, 395-413.

(3) Ding, J. W.; Qin, W. Recent advances in potentiometric biosensors. TrAC, Trends Anal. Chem. 2020, 124, No. 115803.

(4) Hein, R.; Beer, P. D.; Davis, J. J. Electrochemical anion sensing: supramolecular approaches. Chem. Rev. 2020, 120, 1888-1935.

(5) Zahran, E. M.; Fatila, E. M.; Chen, C.; Flood, A. H.; Bachas, L. G. Cyanostar: C-H hydrogen bonding neutral carrier scaffold for anion-selective sensors. Anal. Chem. 2018, 90, 1925-1933.

(6) Zahran, E. M.; Hua, Y. R.; Li, Y. J.; Flood, A. H.; Bachas, L. G. Triazolophanes: a new class of halide-selective ionophores for potentiometric sensors. Anal. Chem. 2010, 82, 368-375.

(7) Langton, M. J.; Serpell, C. J.; Beer, P. D. Anion recognition in water: recent advances from a supramolecular and macromolecular perspective. Angew. Chem., Int. Ed. 2016, 55, 1974-1987.

(8) Sabek, J.; Adriaenssens, L.; Guinovart, T.; Parra, E. J.; Rius, F. X.; Ballester, P.; Blondeau, P. Chloride-selective electrodes based on "two-wall" aryl-extended calix[4]pyrroles: combining hydrogen bonds and anion-pi interactions to achieve optimum performance. Chem. Eur. J. 2015, 21, 448-454.

(9) Liu, Y. L.; Qin, Y.; Jiang, D. C. Squaramide-based tripodal ionophores for potentiometric sulfate-selective sensors with high selectivity. Analyst 2015, 5317-5323.

(10) Cuartero, M.; Ortuno, J. A.; García, M. S.; Sánchez, G.; MásMontoya, M.; Curiel, D. Benzodipyrrole derivates as new ionophores for anion-selective electrodes: Improving potentiometric selectivity towards divalent anions. Talanta 2011, 85, 1876-1881.

(11) Markovich, D. Physiological roles and regulation of mammalian sulfate transporters. Physiol. Rev. 2001, 81, 1499-1533.

(12) Gomez, G. G.; Sandler, R. S.; Seal, E., Jr High levels of inorganic sulfate cause diarrhea in neonatal piglets. J. Nutr. 1995, 125, $2325-2332$

(13) Riel, A. M. S.; Rowe, R. K.; Ho, E. N.; Carlsson, A. C.; Rappe, A. K.; Berryman, O. B.; Ho, P. S. Hydrogen bond enhanced halogen bonds: a synergistic interaction in chemistry and biochemistry. Acc. Chem. Res. 2019, 52, 2870-2880.

(14) Gale, P. A.; Ho, E. N. W.; Wu, X.; Spooner, M. J. Anion receptor chemistry: highlights from 2016. Coord. Chem. Rev. 2018, $375,333-372$. 
(15) Molina, P.; Zapata, F.; Caballero, A. Anion recognition strategies based on combined noncovalent interactions. Chem. Rev. 2017, 117, 9907-9972.

(16) Pancholi, J.; Beer, P. D. Halogen bonding motifs for anion recognition. Coord. Chem. Rev. 2020, 416, No. 213281.

(17) Zahran, E. M.; Hua, Y. R.; Lee, S.; Flood, A. H.; Bachas, L. G. Ion-selective electrodes based on a pyridyl-containing triazolophane: altering halide selectivity by combining dipole-promoted cooperativity with hydrogen bonding. Anal. Chem. 2011, 83, 3455-3461.

(18) Pankratova, N.; Cuartero, M.; Jowett, L. A.; Howe, E. N. W.; Gale, P. A.; Bakker, E.; Crespo, G. A. Fluorinated tripodal receptors for potentiometric chloride detection in biological fluids. Biosens. Bioelectron. 2018, 99, 70-76.

(19) Nishizawa, S.; Buhlmann, P.; Xiao, K. P.; Umezawa, Y. Application of a bis-thiourea ionophore for an anion selective electrode with a remarkable sulfate selectivity. Anal. Chim. Acta 1998, 358, 35-44.

(20) Fibbioli, M.; Berger, M.; Schmidtchen, F. P.; Pretsch, E. Polymeric membrane electrodes for monohydrogen phosphate and sulfate. Anal. Chem. 2000, 72, 156-160.

(21) Qin, L.; Hartley, A.; Turner, P.; Elmes, R. B. P.; Jolliffe, K. A. Macrocyclic squaramides: anion receptors with high sulfate binding affinity and selectivity in aqueous media. Chem. Sci. 2016, 7, 45634572 .

(22) Qin, L.; Wright, J. R.; Lane, J. D. E.; Berry, S. N.; Elmes, R. B. P.; Jolliffe, K. A. Receptors for sulfate that function across a wide $\mathrm{pH}$ range in mixed aqueous-DMSO media. Chem. Commun. 2019, 55, 12312-12315.

(23) Qin, L.; Vervuurt, S. J. N.; Elmes, R. B. P.; Berry, S. N.; Proschogo, N.; Jolliffe, K. A. Extraction and transport of sulfate using macrocyclic squaramide receptors. Chem. Sci. 2020, 11, 201-207.

(24) Custelcean, R.; Bock, A.; Moyer, B. A. Selectivity principles in anion separation by crystallization of hydrogen-bonding capsules. $J$. Am. Chem. Soc. 2010, 132, 7177-7185.

(25) Hay, B. P.; Firman, T. K.; Moyer, B. A. Structural design criteria for anion hosts: strategies for achieving anion shape recognition through the complementary placement of urea donor groups. J. Am. Chem. Soc. 2005, 127, 1810-1819.

(26) Dungan, V. J.; Ngo, H. T.; Young, P. G.; Jolliffe, K. A. High affinity sulfate binding in aqueous media by cyclic peptides with thiourea arms. Chem. Commun. 2013, 49, 264-266.

(27) Jia, C. D.; Wu, B.; Li, S. G.; Huang, X. J.; Zhao, Q. L.; Li, Q.; Yang, X. Highly efficient extraction of sulfate ions with a tripodal hexaurea receptor. Angew. Chem., Int. Ed. 2011, 50, 486-490.

(28) Guilbault, G. G.; Durst, R. A.; Frant, M. S.; Freiser, H.; Hansen, E. H.; Light, T. S.; Pungor, E.; Rechnitz, G.; Rice, N. M.; Rohm, T. J.; Simon, W.; Thomas, J. D. R. Recommendation for nomenclature of ion-selective electrodes. Pure Appl. Chem. 1976, 48, 127-132.

(29) Mi, Y. M.; Bakker, E. Determination of complex formation constants of lipophilic neutral ionophores in solvent polymeric membranes with segmented sandwich membranes. Anal. Chem. 1999, $71,5279-5287$.

(30) Busschaert, N.; Karagiannidis, L. E.; Wenzel, M.; Haynes, C. J. E.; Wells, N. J.; Young, P. G.; Makuc, D.; Plavec, J.; Jolliffe, K. A.; Gale, P. A. Synthetic transporters for sulfate: a new method for the direct detection of lipid bilayer sulfate transport. Chem. Sci. 2014, 5, $1118-1127$

(31) Pietrzak, M.; Meyerhoff, M. E.; Malinowska, E. Anal. Chim. Acta Polymeric membrane electrodes with improved fluoride selectivity and lifetime based on $\mathrm{Zr}(\mathrm{IV})$ - and $\mathrm{Al}(\mathrm{III})$-tetraphenylporphyrin derivatives. Anal. Chim. Acta 2007, 596, 201-209.

(32) Li, L.; Zhang, Y. H.; Li, Y.; Duan, Y. H.; Qian, Y.; Zhang, P. D.; Guo, Q. J.; Ding, J. W. Polymeric Membrane Fluoride-Selective Electrodes Using Lewis Acidic Organo-Antimony(V) Compounds as Ionophores. ACS Sens. 2020, 3465-3473. 